\title{
Mapping the multi-faceted: Determinants of uncertainty in safety-critical projects
}

Fiona C Saunders ${ }^{\mathrm{a}}$, Andrew W Gale ${ }^{\mathrm{a}}$ and Andrew H Sherry ${ }^{\mathrm{b}}$

a School of Mechanical, Aerospace and Civil Engineering, The University of Manchester, Pariser Building, Sackville Street, Manchester M13 9PL, United Kingdom

${ }^{\mathrm{b}}$ National Nuclear Laboratory, Chadwick House, Warrington Road, Birchwood Park, Warrington, WA3 6AE, United Kingdom

\begin{abstract}
Project managers tasked with delivering safety-critical projects must demonstrate care, competence and confidence right from the earliest stages of project inception, when levels of uncertainty can be very high. Based on interviews with 30 project management practitioners in civil nuclear and aerospace sectors, this paper builds on work by Saunders et al. (2015), who posited the Uncertainty Kaleidoscope as a framework for identifying uncertainties.
\end{abstract}

Our findings are that the six determinants of project uncertainty are similar across both civil nuclear and aerospace projects. The most commonly mentioned determinant of project uncertainty was the Environment, followed by Complexity, Capability and Information. The impact of Time on project uncertainty and Individual perceptions of uncertainty were mentioned less frequently by respondents.

Our key contribution is to validate the Uncertainty Kaleidoscope over a larger data set, thereby enriching our understanding of the sources of project uncertainty in these two important and highly-consequential project environments.

\section{Keywords: Project uncertainty; safety-critical; large-scale projects}

\footnotetext{
${ }^{1}$ Corresponding Author at: School of Mechanical, Aerospace and Civil Engineering, The University of Manchester, Pariser Building, Sackville Street, Manchester M13 9PL, UK. Tel 0044161 3063738: Email: fiona.saunders@manchester.ac.uk
} 


\section{Introduction}

Large scale engineering projects are central to modern society. Without them there would be no reliable infrastructure, iconic buildings or inspiring Olympic Stadia. However, one of the myriad challenges facing these projects is how to adequately identify and manage project risks, uncertainties and complexities in order to minimise the potential for failure (PMI, 2013). In safety-critical projects - where safety is of paramount importance and where the hazards that must be controlled can harm the environment, personnel, or the public (Wears, 2012) - the delivery of safe and reliable projects is an absolute imperative. Here project objectives such as schedule and cost are always subordinate to the absolute priority afforded to safety (Kettunun et al., 2007; Saunders, 2015). In safety-critical projects individuals must bear the burden for projects, whose timescales are often long, budgets vast and technical complexity high, and where the consequences of failure may be catastrophic (Reiman and Oedewald, 2009). Irrespective of whether the project is to safely decommission nuclear reactors or design the next generation civil airliners, the project landscape will be dominated by regulatory requirements and the need to be in control at all times (Hollnagel et al., 2006; Laporte and Thomas, 1995). Identifying the sources of, and influences on, uncertainty in these safety-critical projects is an essential task for the project management practitioner throughout the project lifecycle.

Uncertainty in its broadest sense is a state of unknowing - where an individual does not have full knowledge of the facts about a particular situation (Perminova et al., 2008). Uncertainty pervades our daily lives and has been studied through the lens of several academic disciplines from economics, psychology and mathematics to philosophy (see for instance Bammer and Smithson, 2009; Osman, 2010). In the context of projects, the APM defines project uncertainty as "a state of incomplete knowledge about a proposition. Usually associated with risk, both threats and opportunities" (Association of Project Management, 
2006, p. 6). The extant literature on the management of project uncertainty provides us with a number of definitions of project uncertainty, including differentiating it from project risk (Grote, 2015; Hillson, 2002; Sanderson, 2012; Chapman and Ward, 2011); discusses how uncertainty arises in projects (Atkinson et al., 2006; Cleden, 2009; Martinsuo et al., 2014; Saunders et al., 2015; Ward and Chapman, 2003; Winch, 2010) and proffers a variety of approaches to managing project uncertainty (Atkinson et al., 2006; Browning, 2014; Cleden, 2009; Hillson, 2002; Loch et al., 2006; Martinsuo et al., 2014; Perminova et al., 2008; Saunders et al., 2015; Vidal, 2015).

However there are no major studies of uncertainty in safety-critical projects, other than a small exploratory study by Saunders et al. (2015). Given the centrality of safetycritical industries to modern life, and recent calls in the project management literature to replicate rather than reinvent project management research (Horner Reich et al., 2013), our aim here is to refine and validate the earlier exploratory study (Saunders et al., 2015) on a larger and more purposefully selected data set. This will enrich our understanding of the sources of, and influences on project uncertainty in these highly-consequential project environments.

Our analysis is based on semi-structured interviews with 30 project management practitioners on nine large scale projects in civil nuclear and aerospace industries in the United Kingdom. It addresses three key research questions:

RQ1: Whether and how the Uncertainty Kaleidoscope (the previously posited framework for conceptualising the determinants of project uncertainty by Saunders et al., 2015) will evolve after refinement and validation on a larger study of safety-critical projects?

RQ2: What are the commonalities in the determinants of uncertainty between civil nuclear and civil aerospace sectors and across different project types (new build/new product introduction (NPI) versus maintenance projects)? 
RQ 3: What are the differences in the determinants of uncertainty between civil nuclear and civil aerospace sectors and across different project types (new build/new product introduction (NPI) versus maintenance projects)?

Validating and refining the Uncertainty Kaleidoscope over a much larger data set will provide project management practitioners with a framework to identify project uncertainties, thereby reducing the emergence of 'unknowns' that may delay project implementation, add additional costs and reduce stakeholder confidence in the project delivery team. It is important to note that this particular study is limited to the context of safety-critical projects, as this is consistent with the earlier exploratory study that we are seeking to validate. We acknowledge that the uncertainty kaleidoscope may have wider application across a range of project sectors, but this empirical work lies outside the scope of this paper.

\section{Literature review}

\subsection{Uncertainty is a multi-faceted concept}

Uncertainty is a concept that is rich, evocative and loaded with meaning. Uncertainty can conjure up fear and trepidation, or alert one to future opportunities that can be explored, depending on the perspective taken. An entrepreneur may look favourably on uncertainties within a particular market which he can exploit. In contrast, a project manager may fear the consequences of an uncertain future generated by an organisational restructure. What is clear from these two examples is that "uncertainty" is neither a simple nor inconsequential term. Instead it is a multi-faceted concept; one that has been studied across a broad range of intellectual disciplines. To the mathematical mind, uncertainty may imply probabilities of outcome (Attewell, 2009); to the psychologist the debate centres on the extent to which uncertainty is an objective or subjective phenomenon (Head, 1967; Kahnemann and Tversky, 1982; March and Simon, 1958), and to the business executive the presence of future 
uncertainties underlies most strategic decisions (cf. Harrison, 1992; Porter, 1980; Sutcliffe and Zaheer, 1998).

Within the domain of project management a number of scholars have articulated the possible sources of uncertainties in projects. Complexity arising from product requirements, the technology choices made or the variety of actors involved in the project is one such source of uncertainty (Cleden 2009; Martinsuo et al., 2014; Winch, 2010). Weick (1995) lists information load (the volume of ambiguous information that must be processed) and turbulence (the rate at which project facts change and the randomness of their timing and direction of change) as two further sources of uncertainty. Uncertainty may also arise due to factors in the external environment, for example, institutional decision making processes, or from external market or competitor actions (Aaltonen, 2011; Winch, 2010). A final source of project uncertainty arises at an individual level: for example, different personality types may view uncertainty very differently (Madsen and Pries-Heje, 2009), with uncertainty being seen as a subjective phenomenon ( Head, 1967; Perminova et al., 2008).

Chapman and Ward (2011) argue that uncertainty arises through each of 7W's of projects (who the various parties involved are, what they wish to achieve, what the shape of the final project deliverable is, how the project delivery mechanism is set up, what key resources are required to execute the plans, when do the key project events have to take place and finally where will the project take place). Other scholars categorise the sources of uncertainty; for example into environmental, organisational, technical and resources (Colarelli O’Connor and Rice, 2013); into stakeholders, external context, organisational context and management processes (Lechler et al., 2014) or in terms of the inherent properties of a project (complexity, complicatedness, dynamism and interconnectedness) (Ramesh and Browning, 2014). Chapman and Ward (2011) acknowledge that many of these 
sources are not independent of one another, and that their interaction with one another can lead to sizeable impacts on projects.

\subsection{Introducing the Uncertainty Kaleidoscope}

Following a review of the literature on uncertainty and a small exploratory empirical study, Saunders et al. (2015) categorised the sources of uncertainty in the particular context of safety-critical projects. These are the complexity of the project, the environment in which it is being delivered, the capability of both the project team and the wider supply chain, temporal issues such as the timescales and speed of the project, the availability of information and individual team member perceptions of uncertainty. Each of these six determinants of project uncertainty can be further broken down into a number of different components. For example, environmental uncertainty may emerge through external factors such as political, market or competitor activity or may arise as a result of organisational culture, specific norms of behavioural or decision making processes. Information uncertainty is similarly subdivided into an absence of information, lack of knowledge, inadequate understanding of cause and effect relationships, poor estimating ability and lack of clarity of project objectives. Many of the components of the Uncertainty Kaleidoscope are also interrelated, for instance the number and diversity of actors on a project impacts both its complexity and also the environmental uncertainty through the range of stakeholder demands that the project may face. Both these components will shape the overall level of uncertainty on the project. Saunders et al. (2015) synthesised these various sources of uncertainty into the "Uncertainty Kaleidoscope" - see Figure 1 below.

\section{INSERT FIGURE 1}

The Uncertainty Kaleidoscope evolved from a systematic review of the literature on project uncertainty and interviews $(n=8)$ with project management practitioners in both civil 
nuclear and civil aerospace industries (Saunders et al., 2015). Topics in normal text in Figure 1 were reported in the literature and topics in italics emerged during the eight interviews. The framework is in the form of a kaleidoscope as a metaphor for understanding project uncertainty. It reflects a key similarity between large scale projects and the eponymous children's toy; in that a kaleidoscope can generate a multiplicity, perhaps even an infinite number of distinct landscapes of project uncertainty from the same six determinants complexity, environment, capability, time, information and individual. New uncertainties may also emerge as the project progresses. This is equivalent to the kaleidoscope being shaken, which may lead to the emergence of a very different project landscape. For example, the 'as built' drawings of a nuclear reactor may be insufficiently accurate to prevent major new uncertainties emerging during the project to decommission the site and return it to a clean state. Conversely a gas turbine engine on the engine test-bed may deliver test data that does not fit the theoretical models by which the engine has been designed. Many months of work and large additional expenditures may be necessary to correct the engine design and allow it to be certified to fly. These sudden changes in project landscape, often small but on occasion highly consequential, can affect the likelihood of the project objectives being achieved, or may even lead to new project objectives being necessary. Finally, it is important to note that the utility of the Uncertainty Kaleidoscope does not lie in its predictive power, but as a visual framework to enable project practitioners in safety-critical environments to discuss and debate where uncertainty may reside in projects, before it causes unwelcome surprises within the project team.

The key limitation of the Uncertainty Kaleidoscope, as presented in Figure 1, is that it had only been tested on a small sample of project management practitioners. In order to refine and validate the Kaleidoscope, it was necessary to extend the earlier exploratory study to a much larger number of project management practitioners employed on a wider range of 
safety-critical projects in both civil nuclear and civil aerospace sectors. This was the primary purpose of the study reported on here.

Given the diverse range of projects undertaken in these highly consequential settings, we also wanted to establish whether there were common sources of uncertainty between the sectors and also between different project types, which would require us to tailor the Uncertainty Kaleidoscope for a particular project context.

\section{Methodology}

The methods we used here are consistent with those described in the smaller scale study reported in Saunders et al., 2015, as our aim was to refine and validate the Uncertainty Kaleidoscope against a larger dataset. Thus we adopted a qualitative approach, comprising semi-structured interviews with 30 project management practitioners involved in nine largescale safety-critical projects in the UK. Only one of the nine projects (new nuclear power plant - CN4) had formed part of the previous small-scale study. The projects were purposefully chosen to represent both civil nuclear and civil aerospace sectors (there were five nuclear and four aerospace projects drawn from six different organisations) and to reflect two major types of project -"new build/new product introduction projects" and "maintenance projects". For example, new build/NPI projects in the study ranged from the development of the next generation gas turbine engine to the building of new nuclear power plants and test facilities. Maintenance projects included the decommissioning and clean-up of the former sites of nuclear power stations, solving technical challenges in existing reactors to extend their safe operating life and retrofitting safety-critical aircraft assemblies to reduce their maintenance requirements or increase efficiency. The projects were all being delivered by large private sector organisations, and were selected based on their fit with the two project types above and their accessibility to the authors. The projects ranged in value from $£ 25$ Million to upwards of $£ 10$ Billion, and each was at different stages of their lifecycle from 
initial design to testing and commissioning. Selecting two different project types and two distinct industry sectors enabled us to identify any differences between the determinants of uncertainty between sectors and across project types, thereby improving the potential usefulness of the Uncertainty Kaleidoscope to the project management community.

The 30 interviews were undertaken face-to-face at the project sites between March and September 2014. Between two and four respondents per project were interviewed, in order to minimise individual respondent bias and to allow more valid cross-project comparisons to be undertaken. Selection of respondents was by intensity sampling, which is a type of purposeful sampling that selects respondents who are experts about a particular experience (Morse, 1984). All respondents held key project roles such as Programme Manager, Subproject Manager, Project Technical Lead or Commercial Manager. A complete list of the projects and the respondents is provided in Table 1 below. All specific project data has been anonymised due to the confidentiality restrictions in these organisations.

\section{INSERT TABLE 1}

During the interviews respondents were asked to provide demographic information, and then to give an overview of the project and their role in it. Respondents were intentionally not shown the Uncertainty Kaleidoscope either before or during the interviews. Instead respondents were asked "What are the determinants of project uncertainty in this particular project, where determinant means the sources of, and influences on, project uncertainty?" This part of the interviews lasted between 25 and 35 minutes. Later in the interviews respondents were questioned about how they manage project uncertainty but this analysis is outside the scope of this paper. All interviews except one were audio-recorded and later transcribed (one respondent did not allow the use of the voice recorder and written notes from the interview, approved by the respondent, were used). 
The transcribed interviews were analysed using content analysis, which is a technique "where the researcher interrogates the data for constructs and ideas that have been decided in advance” (Easterby-Smith et al., 2008, p173). In content analysis, a set of categories are established - in this case from the earlier Uncertainty Kaleidoscope (Saunders et al., 2015) and the number of instances of each category counted. The a priori identification and systematic counting of these specific categories in the interview transcripts allows inferences to be made from this set of data (Stone et al., 1966). In this study, one 'count' was recorded if a respondent mentioned a particular category of project uncertainty: irrespective of the number of times that the category was mentioned within the same interview.

Validity and reliability in content analysis is directly impacted by the level of intercoder reliability - the consistency of agreement between two or more coders. Consistent with Evans (1996) and Neuendorf (2002) this study used one main coder, with a second coder undertaking a reliability check on the coding counts and categories. During this corroboration process one new category emerged - that of client capability. This new category was added to the analytical categories and the number of 'counts' checked again by the main coder.

During the analysis process a small number of other new components of uncertainty emerged that had not previously been identified during the earlier exploratory study. These were also added to the analytical categories, and the Uncertainty Kaleidoscope revised to take account of them. The findings of this study should be generalisable to other safety-critical projects in the civil nuclear and civil aerospace sectors, given that the sample (nine safety-critical projects) is sufficiently large and varied to be representative of projects in these sectors.

\section{Results}

The findings of this study are structured around the three research questions. First, the content analysis of the 30 interviews is presented and its implications for the validity and 
refinement of the Uncertainty Kaleidoscope discussed. Secondly, commonalities in the determinants of uncertainty across civil nuclear and civil aerospace sectors are identified. Thirdly, any differences between the two sectors are reported and a final section highlights any commonalities and differences between the two selected project types.

\subsection{RQ1: Validation and refinement of the Uncertainty Kaleidoscope}

The interview data set which formed the basis for the content analysis comprised 18 interviews with civil nuclear project management practitioners and 12 interviews with civil aerospace project management practitioners. This imbalance between civil nuclear and aerospace data was not intentional but rather a manifestation of the difficulty in gaining researcher access to these commercially sensitive project environments. The categories and counts for the content analysis are provided in Table 2 . In order to compare the two sectors directly the number of counts is expressed in terms of number of counts per total number of interviews in that sector.

\section{INSERT TABLE 2}

All the analytical categories are drawn from the Uncertainty Kaleidoscope shown in Figure 1, with the exception of integration issues (uncertainties in how the constituent parts of the project design would come together), clarity of roles and responsibilities, project funding, site security (uncertainties in contractors gaining access to secure sites), project scope clarity and client capability which were raised by respondents during the interviews and were added to the list of categories. The emergence of these new categories did not materially impact the Uncertainty Kaleidoscope as they fitted into the existing six top level determinants of uncertainty - for example integration issues contribute to Complexity, whilst funding and site security were classified as Environmental determinants of uncertainty. Data 
saturation (Guest et al., 2006) was observed in this study, with no new categories being raised after Interview 22.

The results of the content analysis were compared with the earlier version of the Uncertainty Kaleidoscope (depicted in Figure 1), enabling it to be both refined and validated. The refined model is shown in Figure 2 below.

\section{INSERT FIGURE 2}

The refined Uncertainty Kaleidoscope illustrates the 6 determinants of project uncertainty. Each determinant comprises a number of more specific and detailed subcomponents. There are a small number of differences in nomenclature between the earlier and refined version of the model; with Temporal renamed as Time, and Environmental renamed Environment. The components of Individual and Information remain unchanged but additional components have been added to Capability (client capability), Complexity (integration issues), Time (changes in scope, information and priorities) and Environment (project funding and clarity of roles and responsibilities).

\subsection{RQ2: Commonalities in the determinants of uncertainty between civil nuclear and aerospace sectors}

Figure 3 demonstrates that the six key determinants of project uncertainty (Complexity, Time, Environment, Capability, Individual and Information) are very similar across both civil nuclear and civil aerospace sectors. The most commonly mentioned determinant of project uncertainty is the Environment, followed by Complexity, Capability and Information. The impact of Time on project uncertainty and Individual perceptions of uncertainty were mentioned much less frequently by respondents.

\section{INSERT FIGURE 3}


Figures 4-9 increase the granularity of analysis to the specific sub-components of uncertainty. At this level of detail, we see that four of the determinants remain broadly similar across the two industry sectors (Complexity, Information, Time and Individual) and two highlight important differences (Environment and Capability).

\section{INSERT FIGURE 4}

In both civil nuclear and aerospace the complexity (see Figure 4) of the functional requirements of the product (for example, the range of nuclear materials that a test facility had to be able to characterise), was the most oft-mentioned determinant of project uncertainty. This was followed by the diversity of actors and stakeholders (ranging from the project team, the wider technical community, to regulators) many of whom were able to mandate changes in scope, or project requirements or delivery timescales for the project. This uncertainty is exemplified by this quotation from CA2

"Approvals have to go through our initial customer, so we go through them and then it goes all the way up to the engine manufacturer and then the air-framer and the airline operators - this is a big uncertainty."

Other less often mentioned subcomponents were technical novelty (when and how to implement new technologies within the project) and the impact of inherent system instability, emergent properties and issues of how to integrate different component parts of complex, highly interconnected engineering systems. Uncertainties in integration were not raised in the earlier study, but were highlighted by seven respondents in this study, as exemplified here: "The challenge on this project is an order of magnitude greater in terms of integration. It's very congested buildings, very close working, lots of difficult access problems and I foresee 
integration of all the work that needs to be done as a mammoth challenge for us. So I think there is a huge level of uncertainty around that" Programme Manager CN4.

\section{INSERT FIGURE 5}

Figure 5 depicts the similarity between civil nuclear and aerospace sectors in terms of Information as a determinant of project uncertainty. The overwhelming majority of Information uncertainty arose from missing or incomplete information or a lack of knowledge or understanding. In the nuclear sector missing information included poor past record keeping over what materials were stored where, and a lack of 'as built' drawings of old facilities, as evidenced on CN1 here:

"We have uncertainty around the waste we are going to put in the containers. That's because the source facilities at $[\mathrm{X}]$ from which the waste is being removed have a chequered past and the record keeping and continuity of knowledge hasn't been maintained."

In addition, many nuclear subsystems, for example the performance of graphite bricks under seismic load, was chaotic, scattered and extremely dynamic, making it hard to understand the causes of differences between modelled and experimental test results, and impacting on the preparation of essential safety cases. In civil aerospace projects, Information uncertainty often concerned an inability to frame the problem correctly, to understand the input parameters or to develop sufficient confidence in a new engine through analytical modelling before an expensive test engine was subjected to the rigours of the engine test bed.

\section{INSERT FIGURE 6}

The similarity in shape of both polar diagrams in Figure 6 also indicates broad agreement across both sectors as to the role of Time as a determinant of project uncertainty. 
In both civil nuclear and aerospace projects the greatest contributor to temporal uncertainty is project turbulence, which manifests itself as changes in project scope, objectives and priority. Projects delivering safety-critical aircraft subsystems reported continual uncertainty over both scope and schedule as captured succinctly here on CA2:

"We are constantly uncertain about when we're going to start and when the [subsystem] qualification will be complete. We are constantly uncertain about scope - is it going to change?"

A nuclear decommissioning project (CN5) also faced repeated changes in project scope, requirements and permitted methods of working which delayed the project and damaged client-contractor relationships:

"so when you thought you had something and you are delivering it, they [the client engineers] would change the scope, impose a new set of requirements in terms of documents, or the method of working would no longer be acceptable" Project Manager CN5

Less frequently mentioned contributors to Time uncertainty were the lifecycle stage of the project and the speed and timescale of the overall project although several respondents acknowledged that uncertainties are typically highest at the inception phase of projects and gradually reduce as the project evolves, as argued previously by Atkinson et al.(2006) and Cleden (2009).

\section{INSERT FIGURE 7}

One intriguing finding in this study was the lack of discussion of Individual uncertainty in either sector. Only three civil nuclear respondents and one civil aerospace respondent discussed uncertainty in terms of a state of mind that exists as a response to external triggers. The following quotation from CA3 is indicative in this regard: "You have to live with this 
uncertainty [over manufacturing lead times], while still being able to put a plan together which shows you can deliver a part on a particular date. So you have to guess at this stage and that does make me feel a bit uncomfortable and vulnerable"

Furthermore, there was only one mention of uncertainty that exists in the mind of the one who doubts (from the same civil aerospace respondent). Most respondents in this study across both sectors viewed uncertainty as residing 'out there' in the external world, rather than arising from individual and subjective differences in how uncertainty is perceived.

\subsection{RQ3: Differences in the determinants of uncertainty between civil nuclear and aerospace sectors}

Figures 8-9 illustrate a number of key differences between the two sectors in terms of the subcomponents of two of the six determinants of uncertainty - Environment and Capability.

\section{INSERT FIGURE 8}

The Environment (Figure 8) was the most often mentioned source of uncertainty in projects in both sectors. In the civil nuclear industry, respondents described multiorganisational project environments, replete with diverse organisational cultures, where the 'ways of doing things round here' had yet to be established in the project. The primary challenge facing civil nuclear project managers was not the complexity or novelty of the technical solution, but rather contending with external influences on the project, within a complex emergent organisational setting and satisfying the myriad internal and external stakeholders, many of whom held a metaphorical axe over the project and its continuing existence. This uncertainty was expressed on CN2: 
"So technically you may think you have the answer but is it politically acceptable. Stakeholder management is a big part of what I have to do."

In civil aerospace, environmental uncertainty was most often caused by external market factors, such as global aviation demand, oil prices, industry responses to serious incidents such as the loss of Flights MH370 and MH17 in 2014 (The Guardian, 2014), and changes in requirements or cost pressures from the airline operators and aircraft manufacturers alike. This uncertainty was expressed on all the civil aerospace projects; most notably on CA1:

"Market uncertainty is there too. We will generally have sunk a lot of money into a project before we get a customer, so we have lots of business plans. Some over deliver and some under deliver. The market forecast is impossible to predict."

In civil aerospace projects, Environmental uncertainty also arose from a lack of role clarity within organisations that were frequently being restructured and re-engineered in the pursuit of cost savings and greater organisational efficiency. For example the Deputy Programme Executive on CA3 reported that

"The organizational set up has changed quite a lot recently, and people are struggling to adjust to that and therefore it is not always obvious who the right people to talk to are."

These organisational realignments were a major source of uncertainty for project management practitioners, both in terms of their own careers and in terms of keeping the project on track. Lastly, securing project funding was an ever present source of uncertainty in both civil nuclear and aerospace industries, with project managers often unable to recruit staff due to ongoing funding uncertainties. A lack of funding was used as an excuse for 
inaction at the planning stages of projects, followed by an inevitable rush to deliver the project once funding sanction was given.

\section{INSERT FIGURE 9}

Figure 9 shows further marked differences between the sources of uncertainty around Capability across the two industry sectors. For example, in the civil nuclear sector the majority of the uncertainty emanates from a lack of capability within a long and often fragmented supply chain, as articulated on $\mathrm{CN} 1$ :

"Another uncertainty is supply chain and resources - there has been a lack of investment and attention in the nuclear supply chain and it has withered on the vine."

Lack of attention to the nuclear skills base in the UK (Cogent, 2009) has caused the nuclear supply chain to degrade, leading to big resource challenges for nuclear projects that require nuclear-grade capability from external suppliers. Respondents described a dangerous assumption that was still prevalent within nuclear projects; that there was an unlimited pool of external skilled resources ready and willing to bid for any project work.

This contrasted sharply with the civil aerospace sector, where one of the major areas of uncertainty was securing internal resources, particularly in specific technical disciplines such as design. Civil aerospace project managers often did not control their resources leaving them vulnerable to other project priorities, or even to other projects outbidding them for key staff. A good example of this was shared on CA1:

“just when we think we are okay [Project T] might blow up on the test rig and resources are taken from our project - entire groups of people are just taken off the project.......You can't negotiate priorities - you say I have got a timeline to keep, they say I have got to keep people in the air and it trumps everything. So priorities from other projects kill you" 


\subsection{Commonalities and differences in the determinants of uncertainty between new build/NPI projects and maintenance projects}

A comparable analysis of component uncertainties, broken down by project type and industry sector is not presented here as the numbers of projects in each category are too small to make this analysis a meaningful one. Instead, the analysis focuses on the six determinants of uncertainty and their comparison across different project types. Figure 10 shows the determinants of uncertainty across the two different types of project that were studied (new build/NPI vs maintenance).

\section{INSERT FIGURE 10}

Comparing Figures 3 and 10, we see that the differences between project types are greater than the differences between the two industry sectors. New build/NPI projects reported higher counts of the Environment, Time and Complexity determinants of uncertainty than maintenance projects. The higher reported counts of Environment uncertainty were primarily caused by greater stakeholder and political influences within the large-scale and often high profile civil nuclear new build projects. Similarly, the higher counts of Time as a determinant of uncertainty were also strongly influenced by the lifecycle stage of the nuclear new build projects. Finally, possible explanations for the greater counts of Complexity in new build/NPI projects in both sectors were the increased demand for novel technological solutions in new build/NPI projects in contrast to the more incremental solutions that were pursued in maintenance projects. This in turn created typically more complex functional requirements that had to be met in new build/ NPI projects.

Figure 11 compares the six determinants of uncertainty across both different project types and the two industry sectors. It shows that the differences between civil-nuclear new build/NPI and maintenance projects are greater than the differences between those seen 
between civil aerospace new build/NPI and maintenance projects. The civil nuclear new build/NPI projects remain exposed to high levels of Environmental and Time uncertainty in comparison with civil nuclear maintenance projects, whereas the differences between civil aerospace new build/NPI and maintenance projects are less pronounced - with the polar diagrams following a similar shape. The only exception to this is the difference in Individual perception of uncertainty, but this difference is very small, and arises due to the mention of individual perception by two respondents on civil aerospace maintenance projects.

\section{Discussion}

This study has drawn further attention to the dimensions of uncertainty within the specific context of the safety-critical project and how it varies between sectors and across different project types. The findings refine and validate earlier work by Saunders et al. (2015) over a much larger and purposively selected data-set of nine case study projects across both civil nuclear and aerospace sectors. In this discussion section we interpret the outcomes of the study, comparing our findings with other research on the sources of project uncertainty and the earlier posited framework of the Uncertainty Kaleidoscope. This section is again structured around the three research questions.

\subsection{RQ1: Validation and refinement of the Uncertainty Kaleidoscope}

Earlier exploratory research (Saunders et al., 2015) posited the Uncertainty Kaleidoscope as a highly visual framework for mapping project uncertainties in safetycritical projects. Our larger scale study analysed 30 respondent interviews, also from safetycritical projects, allowing us to refine and validate the Uncertainty Kaleidoscope as a model for mapping the determinants of project uncertainty in safety-critical projects. Importantly we have also identified which of the six determinants are most prevalent in safety-critical projects; our findings showed that the Environment was the most often mentioned 
determinant of project uncertainty, followed by Complexity, Capability then Information. The impact of Time on project uncertainty and Individual perceptions of uncertainty were highlighted much less frequently. The Uncertainty Kaleidoscope builds on earlier efforts (by Colarelli O’Connor and Rice, 2013; Lechler et al., 2014; Martinsuo et al., 2014 and Ramesh and Browning, 2014) to categorise the sources of uncertainty in different project contexts. It is however the first framework to be developed for the specific context of the safety-critical project and the first to rank the prevalence of the different sources of uncertainty. Validating the Uncertainty Kaleidoscope is an important contribution to research, as safety-critical projects do exhibit nuances and tensions that may not manifest themselves in other less highly consequential environments. Two such tensions are the ever present trade-off between profitability and safety (Reiman and Rollenhagen, 2012), and the tension between the provision of redundancy versus the risk of increasing the complexity of the system (Ripjma, 1997). Somewhat paradoxically additional redundancy may challenge safe operation as it adds additional complexity to a system, makes systems less transparent, and can give a false sense of security in safety margins (Kettunun et al., 2007). Consequently, the technology solutions adopted by safety-critical projects are often complex and always subject to extensive regulatory requirements (Hollnagel et al., 2006; La Porte and Thomas, 1995). As stated earlier, ultra-safe design and operation is the key aim of all safety-critical projects (Amalberti, 2001). However this overarching focus on safety can lead to extensive procedures and regulations, the use of conservative and often aging technology and often rigid and bureaucratic hierarchies of control (Kettunun et al., 2007). These unique characteristics of safety-critical projects perhaps explain the high prevalence of Environment and Complexity uncertainty in our study.

As already acknowledged, the utility of Uncertainty Kaleidoscope lies not in its predictive power, but as a validated model to help project practitioners visualise the myriad 
landscapes of project uncertainty that may arise in safety-critical projects and better identify and assess where areas of uncertainty may reside. Like many metaphor based models it is intended to be memorable and to act as a visual tool, enabling productive discussion and debate about the sources of uncertainty at each stage of a project's lifecycle. Like all metaphors it has limitations and the authors acknowledge the weaknesses inherent in using a kaleidoscope as a metaphor for projects. After all the very purpose of a kaleidoscope is to be shaken to make new patterns, in contrast to projects, which in an ideal world would remain stable and not subject to violent perturbation.

In spite of this limitation, we argue that using the Uncertainty Kaleidoscope to explicitly identify, characterise and debate uncertainty may increase project managers' confidence in addressing the uncertainties with which they are confronted. As a minimum it should enable areas of uncertainty to be identified and explored, rather than ignored or overlooked (Lechler et al., 2014). As an added benefit it may also lead to a gradual change in perspective from uncertainty as risky, problematic and something to be feared, to uncertainties as potential opportunities, from which the project may exploit and profit as argued by Hillson (2004), Olsson, (2007) and Schlesinger et al. (2012).

\subsection{RQ2: Commonalities in the determinants of uncertainty between civil nuclear and aerospace sectors}

This study has demonstrated that the six determinants of project uncertainty (Complexity, Time, Environment, Capability, Individual and Information) are broadly similar across both civil nuclear and civil aerospace sectors. At the more detailed sub-component level of project uncertainty we found that the components of Complexity, Information, Time and Individual sources of uncertainty were similar across the two sectors and for the most part consistent with other research studies. For example, our findings on Complexity support 
earlier work by Danilovic and Sandkull (2005) and Reyman et al. (2008) that the Complexity determinant of uncertainty is strongly influenced by uncertainty in the functional requirements of the project and the wide diversity of actors in stakeholders in these multiorganisational, high-profile projects. Consistent with earlier work by Harrison (1992) and Cleden (2009), we also found that the majority of Information uncertainty arose from missing or incomplete information or a lack of knowledge or understanding. The main area of dissonance with earlier research was the lack of mentions of Individual perceptions of uncertainty in this study; which contrasts with a strong theme in the literature (cf. Head, 1967; Kahnemann and Tversky, 1982; Madsen and Pries-Heje, 2009; Perminova et al., 2008). One possible explanation for this could be the engineering backgrounds of many project managers within these sectors, and a culture which focuses on pragmatic problem solving and project delivery rather than agonising over whether uncertainties exist 'out there' or 'in the mind'. Or, it may be that even if project managers are uncertain and unsure, these doubts are internalised and not articulated by individuals who are trained to undertake formal analyses to gain certainty over complicated technical problems (Vidal, 2015). An alternative, although untested, hypothesis could also be that large-scale safety-critical projects tend to attract individuals who are comfortable dealing with high levels of uncertainty. Nevertheless, inspite of the lack of empirical evidence for individual uncertainty we have retained the Individual determinant and its subcomponents within the Uncertainty Kaleidoscope as uncertainty as a subjective phenomenon is such a dominant theme in the academic literature.

The close similarity between many of the sources of uncertainty in civil nuclear and civil aerospace projects is not entirely surprising given the fact that both sectors must deliver complex, large scale engineering projects to demanding safety and performance standards, under the spotlight of powerful and proactive regulatory authorities (La Porte and Thomas, 1995; Saunders, 2015). However one key question, that remains unanswered, is whether the 
ways in which these uncertainties emerge, are assessed and acted upon are also similar across both civil nuclear and aerospace sectors, or whether there are ways of contending with uncertainty that are unique to each sector.

One further observation from the data in Table 2 is the relatively low number of mentions of each subcomponent of uncertainty across all respondents. For example even the most common sub-components of uncertainty were only mentioned by half the respondents. This heterogeneity in individual perceptions of the sources of uncertainty actually provides further empirical evidence for the broad and multi-faceted nature of uncertainty, at least in the safety-critical context. Project uncertainty can manifest itself in myriad ways and arise from a diverse range of sources, even within a single determinant. This serves as further evidence of the utility of the Uncertainty Kaleidoscope as an empirically tested and highly visual framework to encourage project managers to discuss and debate early on where uncertainty may reside, rather than ignoring or hiding from it.

\subsection{RQ3: Differences in the determinants of uncertainty between civil nuclear and aerospace sectors and between project types}

This study identified more pronounced differences between civil nuclear and civil aerospace sectors at the finer granularity of the components of uncertainty that make up each determinant. In particular, the Environment and Capability as sources of project uncertainty each manifest themselves in different ways in the two industry sectors studied. For example Environment uncertainty is more likely to arise due to myriad internal and external stakeholders in nuclear but is caused more by external market and competitive pressures in civil aerospace. And Capability uncertainty pervades the entire nuclear project supply chain whereas it is more focused on internal resource availability in civil aerospace. Both these differences can be explained by the different structural and competitive landscapes in the two industry sectors in the United Kingdom. For example the civil aerospace sector operates 
under immense commercial and cost pressure from airline operators (Lofquist, 2014). Here actions by competitors or new customer demands can cause significant impacts to product development pipelines and available budgets. There is also an established and well-resourced supply chain for civil aerospace projects (Jackson, 2004), meaning that capability issues are more tightly focused on the host project organisation. In contrast, the civil nuclear industry suffers more acutely from political pressure and differing public perceptions of the desirability of nuclear power (Kettunun et al., 2007). As a consequence, civil nuclear projects are exposed to a more diverse group of stakeholders and host project organisations are more likely to subcontract much of the project design and delivery work to $3^{\text {rd }}$ party organisations. This increases the Capability uncertainty in the supply chain which may be simultaneously bidding for multiple decommissioning or maintenance projects as well as ramping up resources to start work on the next generation of nuclear power plants.

We also found evidence of differences in the determinants of project uncertainty between project types, with civil nuclear new build/NPI projects exhibiting higher levels of Environmental and Time uncertainty than civil nuclear maintenance projects. It is difficult to draw generalisable conclusions from this finding, due to the diversity of projects studied from nuclear decommissioning and site clean-up work to the design and build of new nuclear power generation capability. All of the projects studied were also at very different stages in the lifecycle, from inception to final implementation. However our findings do support earlier research by Atkinson et al. (2006) and Winch (2010) that uncertainty will generally reduce as a function of project progress. A more extensive research study, comparing larger numbers of different project types which are at similar stages of the project lifecycle is now required to provide more robust evidence of any significant differences in the determinants of uncertainty across different project types.

\section{Conclusions}


Gaining research access to safety-critical projects can be difficult due to the high levels of commercial sensitivity that prevail in these industries. This study of nine safety-critical projects provided a valuable opportunity to explore these under researched project environments, and has enabled us to make three important contributions to literature and practice. First, we have responded to Horner Reich et al.'s (2013) call for researchers to replicate rather than reinvent project management research by validating the Uncertainty Kaleidoscope as a model for mapping the determinants of project uncertainty in safetycritical projects. Secondly, we have demonstrated that the six major determinants of project uncertainty (Complexity, Time, Environment, Capability, Individual and Information) are broadly similar across both civil nuclear and civil aerospace sectors. Thirdly, we also identified which of the six determinants are most prevalent in safety-critical projects (Environment, followed by Complexity, Capability and Information).

The project management practitioners tasked with managing these complex, large-scale safety-critical projects in civil nuclear and civil aerospace industries have to operate with care, competence and confidence in an environment of high uncertainty. Using the Uncertainty Kaleidoscope to identify the sources of and influences on uncertainty may help these individuals better structure their projects for success and render them less likely to be surprised by 'unknowns' that may delay project implementation, add additional costs and reduce stakeholder confidence in the project delivery team. By identifying areas of uncertainty early on in the project lifecycle, when the scope may be very fluid, costs and timescales little more than unsubstantiated estimates, and the required trade-offs between competing project objectives just beginning to emerge, it may also be possible to reorient project managers' perceptions of project uncertainty as unwanted, negative and bound up with risks to project delivery, into a more expansive, optimistic understanding of uncertainty 
as an opportunity to be exploited with positive approaches for changing how projects are delivered (as argued by Lechler et al., 2014).

\subsection{Limitations and areas for future work}

There are a number of limitations in the research which need to be highlighted. First, the access to projects was to some extent opportunistic. Although strenuous attempts were made to identify a well-balanced portfolio of projects to investigate, access was not always granted within a reasonable timeframe, resulting in an imbalance in interviews between civil nuclear and aerospace projects. Secondly, the interviews provided a snapshot of the sources of uncertainty in the projects; and therefore failed to measure any dynamic properties of the uncertainties and how they might change over the course of a project's lifecycle. Thirdly, although the authors interviewed several respondents per project to minimise individual respondent bias, it was not possible to further triangulate the findings by accessing other sources of data, for example project documentation or participant observation.

Three important areas for future research have also been identified. The first of these would be to investigate the wider applicability of the Uncertainty Kaleidoscope by testing its utility, both in other safety-critical sectors, such as oil and gas and across a broader range of project environments. The second area for future research would be to further quantify the six determinants of uncertainty (and their components); ranking them in terms of impact on safety-critical projects, thereby enabling project managers to focus on the areas of uncertainty with the most material impact on project delivery. Thirdly, given the close similarity in the sources of uncertainty across the two sectors, another important avenue of further research would be to explore whether these uncertainties are identified, assessed and acted upon in a similar manner across civil nuclear and aerospace sectors, or whether there are ways of contending with uncertainty that are unique to each sector. 


\section{Conflicts of interest}

There are no conflicts of interest in this study.

\section{Acknowledgements}

The authors would like to thank two anonymous reviewers, whose detailed, insightful and constructive comments have strengthened the originally submitted manuscript, an earlier version of which was presented at European Academy of Management Conference, June 2015.

\section{References}

Aaltonen, K., 2011. Project stakeholder analysis as an environmental interpretation process. International Journal of Project Management, 29, 165-183.

Amalberti, R., 2001. The paradoxes of almost totally safe transportation systems. Safety Science, 37, 109-126.

Association of Project Management, 2006. APM Body of Knowledge (5th ed.) High Wycombe, UK: Association of Project Management.

Atkinson, R., Crawford, L., Ward, S., 2006. Fundamental uncertainties in projects and the scope of project management. International Journal of Project Management, 24, 687-698.

Attewell, R.G., 2009. Statistics: An essential tool for model citizens, in Bammer, G., Smithson, M. (Eds.), Uncertainty and Risk: Multidisciplinary Perspectives (pp. 81-91). London, UK: Earthscan.

Bammer, G., Smithson, M., 2009. Uncertainty and Risk: Multidisciplinary Perspectives. London, UK: Earthscan.

Browning,T.R., 2014. A quantitative framework for managing project value, risk and opportunity. IEEE Transactions on Engineering Management, 61, 4, 583-598.

Chapman, C.B., Ward, S., 2011. How to Manage Project Opportunity and Risk. Chichester,UK: John Wiley and Sons.

Cleden, D., 2009. Managing Project Uncertainty., Farnham, UK: Gower Publishing Limited.

Colarelli O'Connor, G., Rice, M.P., 2013. A comprehensive model of uncertainty associated with radical innovation. Journal of Product Innovation Management, 30, S1, 2-18.

Cogent, 2009. Power people: The civil nuclear workforce 2009-2025 Renaissance Nuclear Skills Series 1, 2009, http://www.cogent-ssc.com/research/Publications/NuclearReportPowerPeople.pdf. Accessed on 25th January 2016.

Danilovic, M., Sandkull, B., 2005. The use of dependence structure matrix and domain mapping in managing uncertainty in multiple project situations. International Journal of Project Management, 23, 193-203.

Easterby-Smith, M., Thorpe, R., Jackson, P.R., 2008. Management Research. (3rd ed.) London, UK: SAGE Publications Ltd.

Evans, W., 1996. Computer supported content analysis: Trends, tools and techniques. Social Science Computer Review, 14, 3, 269-279.

Grote, G., 2015. Promoting safety by increasing uncertainty - implications for risk management. Safety Science, 71, 71-79.

The Guardian, 2014. Is there a future for Malaysia Airlines after flights MH370 and MH17? http://www.theguardian.com/world/2014/jul/29/is-there-a-future-for-malaysia-airlines. Accessed on 25 th January 2016. 
Guest, G., Bunce, A., Johnson, L., 2006. How many interviews are enough? An experiment with data saturation and variability. Field Methods, 18, 1, 59-82.

Harrison, E.F., 1992. Perspectives on uncertainty in successful strategic choice at the CEO level. OMEGA International Journal of Management Science ,20, 1, 105-116.

Head, G.L., 1967. An alternative to defining risk as uncertainty. The Journal of Risk and Insurance, 2, $34,205-214$.

Hillson, D., 2002. Extending the risk process to manage opportunities. International Journal of Project Management, 20, 235-240.

Hillson, D., 2004. Effective Opportunity Management for Projects- Exploiting Positive Risk. New York: Marcel Dekker.

Hollnagel, E., Woods, D.D., Leveson, N., 2006. Resilience Engineering: Concepts and Precepts. Farnham, UK: Ashgate Publishing Ltd.

Horner Reich, B., Liu, L., Sauer, C., Bannerman, P., Cicmil, S., Cooke-Davies, T., Thomas, J., 2013. Developing better theory about project organizations. International Journal of Project Management, 31, 7, 938-942.

Jackson, I., 2004. The future of the defence firm: the case of the UK aerospace industry. Defence and Peace Economics, 15, 6, 519-534.

Kahneman, D., Tversky, A., 1982. Variants of uncertainty, in Kahneman, D., Slovic, P., Tversky, A. (Eds.), Judgement under uncertainty: Heuristics and Biases (pp. 509-520). Cambridge: Cambridge University Press.

Kettunun, J., Reiman, T., Wahlstrom, B., 2007. Safety management challenges and tensions in the European nuclear power industry. Scandinavian Journal of Management, 23 , 424-44.

La Porte, T.R., Thomas, C.W., 1995. Regulatory compliance and the ethos of quality enhancement: Surprises in nuclear power plant operations. Journal of Public Administration Research and Theory: J-PART, 5,1, 109-137.

Lechler, T.G., Gao, T., Edington, B., 2014. The Silver Lining of Project Uncertainties. Newton Square, PA: PMI Publication.

Loch, C.H., DeMeyer, A., Pich, M.T., 2006. Managing the unknown: A new approach to managing high uncertainty and risk in projects. Hoboken, New Jersey: John Wiley and Sons.

Lofquist, E.A., 2014. The art of measuring nothing: The paradox of measuring safety in a changing civil aviation industry using traditional safety matrices. Safety Science, 48, 1520-1529.

Madsen, S., Pries-Heje, J., 2009. Taking a closer look at uncertainty in IS projects. AMCIS 2009

Proceedings. http://aisel.aisnet.org/amcis2009/119. Accessed on 25th January 2016.

March, J. G., Simon, H.A., 1958. Organisations. NewYork: John Wiley and Sons.

Martinsuo, M., Korhonen, T., Laine, T., 2014. Identifying, framing and managing uncertainties in project portfolio. International Journal of Project Management, 32, 5, 732-746.

Morse,J.M.,1994. Designing Funded Qualitative Research. In: Denzin, N.K., Lincoln, Y.S., (Eds), Handbook of Qualitative Research (pp.220-235). Sage, Thousand Oaks, CA.

Neuendorf, K.A., 2002. The Content Analysis Guidebook. Thousand Oaks, CA: SAGE Publications Inc.

Olsson, R., 2007. In search of opportunity management: is the risk management process enough? International Journal of Project Management, 25, 745-752.

Osman, M., 2010. Controlling Uncertainty: Decision Making and Learning in Complex Worlds. Chichester, UK: Wiley Blackwell.

Perminova, O., Gustafsson, M., Wikstrom, K., 2008. Defining uncertainty in projects: a new perspective. International Journal of Project Management, 26, 73-79.

PMI, 2013. PMI's pulse of the profession: The high cost of low performance. http://www.pmi.org/Learning/ /media/pdf/business-solutions/pmi-pulse\%20report2013 mar4.ashx. Accessed on $25^{\text {th }}$ January 2016.

Porter, M.E., 1980. Competitive Strategy. New York: Free Press.

Ramasesh, R.V., Browning, T.R., 2014. A conceptual framework for tackling knowable unknown unknowns in project management. Journal of Operations Management 32, 190-204.

Reiman, T., Oedewald, P., 2009. Evaluating safety-critical organizations: Emphasis on the nuclear industry. http://www.vtt.fi/inf/julkaisut/muut/2009/SSM-Rapport-2009-12.pdf. Accessed on $25^{\text {th }}$ January 2016. 
Reiman, T., Rollenhagen, C., 2012. Competing values, tensions and trade-offs in the management of nuclear power plants. Work, 41, 722-729.

Reymen, I.M.M.J., Dewulf, G.P.M.R., Blokpoel, S.B., 2008. Framework for managing uncertainty in property projects. Building Research and Information, $36,6,580-592$.

Rijpma, J.A., 1997. Complexity, tight-coupling and reliability: Connecting normal accident theory and high reliability. Journal of Contingencies and Crisis Management, 5, 1, 15-23.

Sanderson, J., 2012. Risk, uncertainty and governance in mega projects. International Journal of Project Management, 30 , 432-443.

Saunders F.C., Gale, A.W., Sherry, A.H., 2015. Conceptualising Uncertainty in Safety-critical projects: a practitioner perspective, International Journal of Project Management, 33,2, 467-478.

Saunders, F.C., 2015. Towards high reliability project organizing in safety-critical projects. Project Management Journal, 46, 3, 25-35.

Schlesinger, L.A., Kiefer, C.F., Brown, P.B., 2012. New project: Don't Analyse-Act in Harvard Business Review, March 2012, 154 -158.

Stone, P.J, Dunphy, D.C., Smith, M.S., Ogilvie, M.N., 1966. The general inquirer: A computer approach to content analysis. Cambridge: MIT Press.

Sutcliffe,K.M., Zaheer,A., 1998. Uncertainty in the transaction environment: an empirical test. Strategic Management Journal, 19, 1-23.

Vidal, R., 2015. Managing uncertainty: the engineer the craftsman and the gardener. Journal of Contingencies and Crisis Management, 23, 2, 106-116.

Ward, S., Chapman, C., 2003. Transforming project risk management into project uncertainty management. International Journal of Project Management, 21, 97-105.

Wears, R.L., 2012. Rethinking healthcare as a safety-critical industry. Work 41, 4560-4563.

Weick, K.E., 1995. Sensemaking in Organizations. Thousand Oaks, CA: Sage Publications Inc.

Winch, G.M., 2010. Managing Construction Projects: An information processing approach, ( $\left.2^{\text {nd }} \mathrm{ed}.\right)$. Chichester, UK: Wiley-Blackwell. 


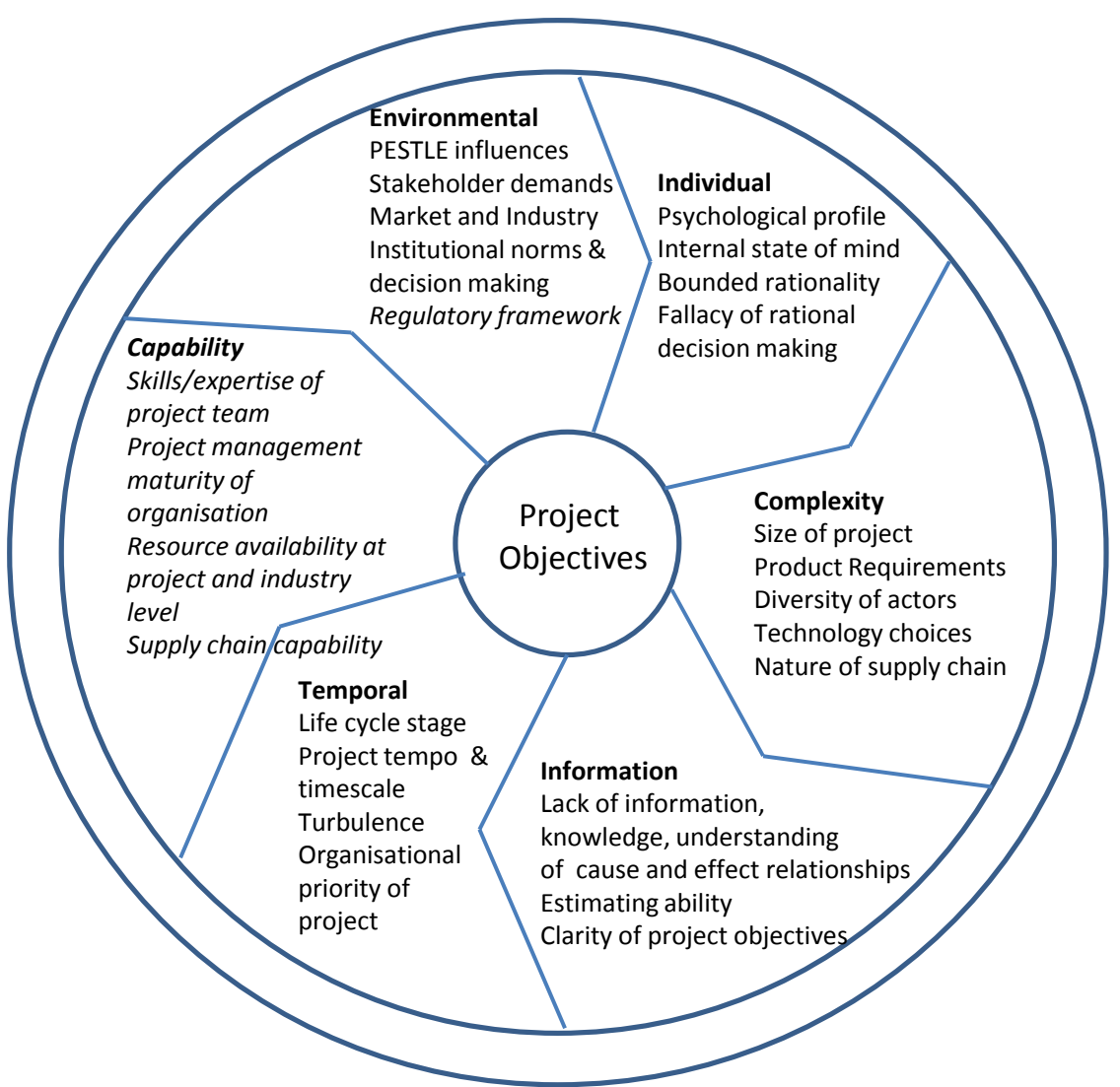

Figure 1: The Uncertainty Kaleidoscope (from Saunders et al., 2015) 


\begin{tabular}{|l|l|l|l|l|}
\hline Project Description & Code & Industry Sector & Project Type & Respondent Roles \\
\hline $\begin{array}{l}\text { Intermediate level } \\
\text { waste (ILW) storage } \\
\text { facility }\end{array}$ & CN1 & Civil Nuclear & maintenance & $\begin{array}{l}\text { Project Engineering Manager } \\
\text { Project Director } \\
\text { Project Controller } \\
\text { Commercial Manager }\end{array}$ \\
\hline $\begin{array}{l}\text { Reactor life-extension } \\
\text { project }\end{array}$ & CN2 & Civil Nuclear & maintenance & $\begin{array}{l}\text { Group Head of Project } \\
\text { Technical Lead } \\
\text { Sub-project Manager } \\
\text { Sub-project Manager }\end{array}$ \\
\hline $\begin{array}{l}\text { Development of new } \\
\text { civil nuclear test } \\
\text { facilities }\end{array}$ & CN3 & Civil Nuclear & $\begin{array}{l}\text { new build/new } \\
\text { product introduction }\end{array}$ & $\begin{array}{l}\text { Senior Project Manager } \\
\text { Project Manager } \\
\text { Risk Analyst }\end{array}$ \\
\hline $\begin{array}{l}\text { Nuclear new build } \\
\text { project }\end{array}$ & CN4 & Civil Nuclear & $\begin{array}{l}\text { new build/new } \\
\text { product introduction }\end{array}$ & $\begin{array}{l}\text { Programme Manager } \\
\text { Programme Manager } \\
\text { Programme Manager } \\
\text { Programme Manager }\end{array}$ \\
\hline $\begin{array}{l}\text { Decommissioning of } \\
\text { specific elements of } \\
\text { nuclear power station }\end{array}$ & CN5 & Civil Nuclear & maintenance & $\begin{array}{l}\text { Project Manager } \\
\text { Commercial Manager } \\
\text { Client account director }\end{array}$ \\
\hline $\begin{array}{l}\text { Development of new } \\
\text { gas turbine engine }\end{array}$ & CA1 & Civil Aerospace & $\begin{array}{l}\text { new build/new } \\
\text { product introduction }\end{array}$ & $\begin{array}{l}\text { Subsystem Programme Manager } \\
\text { Subsystem Programme Manager } \\
\text { Deputy Programme Executive }\end{array}$ \\
\hline $\begin{array}{l}\text { Retrofit of safety- } \\
\text { critical assemblies to } \\
\text { in-service aircraft }\end{array}$ & CA2 & Civil Aerospace & maintenance & $\begin{array}{l}\text { In service Programme manager } \\
\text { Operations Shift Manager } \\
\text { Project Team Leader }\end{array}$ \\
\hline $\begin{array}{l}\text { Phased upgrades to in- } \\
\text { service aircraft }\end{array}$ & CA3 & Civil Aerospace & maintenance & $\begin{array}{l}\text { Deputy Programme Executive } \\
\text { Chief of Subsystem } \\
\text { Integrated Project team Leader } \\
\text { Integrated Project team Leader }\end{array}$ \\
\hline $\begin{array}{l}\text { Development of new } \\
\text { test facility }\end{array}$ & CA4 & Civil Aerospace & $\begin{array}{l}\text { new build/new } \\
\text { product introduction } \\
\text { Project Manager }\end{array}$ \\
\hline
\end{tabular}

Table 1: The projects, their type and list of respondents 


\begin{tabular}{|c|c|c|c|c|}
\hline Determinant & Components of uncertainty & $\begin{array}{l}\text { Civil Nuclear } \\
\text { (Number of } \\
\text { counts/numbe } \\
\text { r of } \\
\text { interviews) }\end{array}$ & $\begin{array}{l}\text { Civil } \\
\text { Aerospace } \\
\text { (Number of } \\
\text { counts/numb } \\
\text { er of } \\
\text { interviews) }\end{array}$ & $\begin{array}{l}\text { Total number of } \\
\text { counts/total } \\
\text { number of } \\
\text { interviews } \\
\text { across both } \\
\text { sectors }\end{array}$ \\
\hline \multirow[t]{4}{*}{ Complexity } & $\begin{array}{l}\text { Functional requirements of the } \\
\text { product }\end{array}$ & 0.5 & 0.4 & 0.5 \\
\hline & Diversity of actors and stakeholders & 0.3 & 0.3 & 0.3 \\
\hline & $\begin{array}{l}\text { Inherent project complexity (including } \\
\text { Feedback loops, instability and } \\
\text { emergent system properties/ } \\
\text { integration issues) }\end{array}$ & 0.3 & 0.2 & 0.2 \\
\hline & Technical novelty & 0.4 & 0.3 & 0.4 \\
\hline \multirow[t]{4}{*}{ Information } & Incomplete and imperfect information & 0.5 & 0.5 & 0.5 \\
\hline & Lack of knowledge or understanding & 0.5 & 0.5 & 0.5 \\
\hline & $\begin{array}{l}\text { Incomplete understanding of cause } \\
\text { and effect relationships }\end{array}$ & 0.1 & 0.0 & 0.1 \\
\hline & Inability to estimate accurately & 0.1 & 0.2 & 0.1 \\
\hline \multirow[t]{6}{*}{ Environmental } & $\begin{array}{l}\text { Environmental turbulence (due to } \\
\text { changes in market, political } \\
\text { environment or competitor activity) }\end{array}$ & 0.4 & 0.7 & 0.5 \\
\hline & $\begin{array}{l}\text { Competing and conflicting } \\
\text { stakeholder demands }\end{array}$ & 0.4 & 0.3 & 0.4 \\
\hline & $\begin{array}{l}\text { Culture (organizational tolerance of } \\
\text { uncertainty, Institutional decision } \\
\text { making processes, clarity of roles and } \\
\text { responsibilities) }\end{array}$ & 0.4 & 0.6 & 0.5 \\
\hline & Regulatory constraints & 0.2 & 0.0 & 0.1 \\
\hline & Site security & 0.2 & 0.0 & 0.1 \\
\hline & Funding & 0.3 & 0.2 & 0.3 \\
\hline \multirow[t]{3}{*}{ Time } & Stage of project lifecycle & 0.2 & 0.3 & 0.2 \\
\hline & Project tempo and timescale & 0.2 & 0.1 & 0.1 \\
\hline & $\begin{array}{l}\text { Project turbulence (rate of change of } \\
\text { project facts, direction of change, } \\
\text { clarity of scope) }\end{array}$ & 0.4 & 0.3 & 0.4 \\
\hline \multirow[t]{4}{*}{ Individual } & $\begin{array}{l}\text { Uncertain state of mind due to } \\
\text { external triggers }\end{array}$ & 0.2 & 0.1 & 0.1 \\
\hline & $\begin{array}{l}\text { Uncertainty exists "in the mind of the } \\
\text { person who doubts" }\end{array}$ & 0.0 & 0.1 & 0.0 \\
\hline & $\begin{array}{l}\text { Bounded rationality and Fallacy of } \\
\text { rational decision making }\end{array}$ & 0.0 & 0.0 & 0.0 \\
\hline & $\begin{array}{l}\text { Different psychological profiles } \\
\text { perceive uncertainty in different ways }\end{array}$ & 0.0 & 0.0 & 0.0 \\
\hline \multirow[t]{5}{*}{ Capability } & Skills and experience of project team & 0.2 & 0.1 & 0.2 \\
\hline & $\begin{array}{l}\text { Project management maturity of } \\
\text { organisation }\end{array}$ & 0.3 & 0.2 & 0.2 \\
\hline & Internal resource availability & 0.3 & 0.5 & 0.4 \\
\hline & $\begin{array}{l}\text { Capability (skills and experience } \\
\text { across industry supply chain) }\end{array}$ & 0.4 & 0.3 & 0.4 \\
\hline & Client capability & 0.2 & 0.1 & 0.1 \\
\hline
\end{tabular}

Table 2: Categories and number of counts/number of interviews (there were 18 civil nuclear and 12 civil aerospace interviews) 


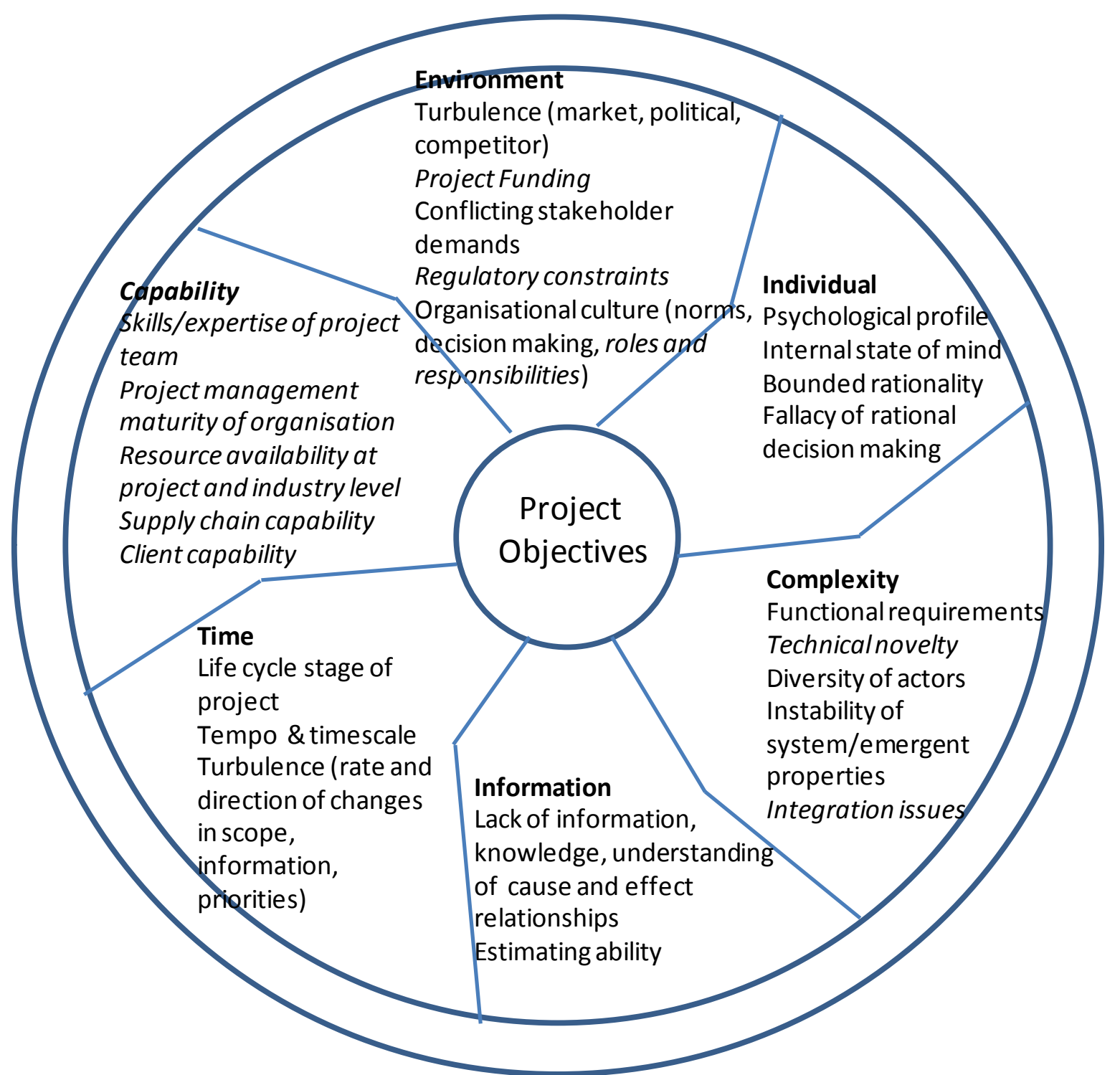

Figure 2: Refined and validated model of the "Uncertainty Kaleidoscope". Components in italics arose from the empirical studies; those in normal text from the literature. 


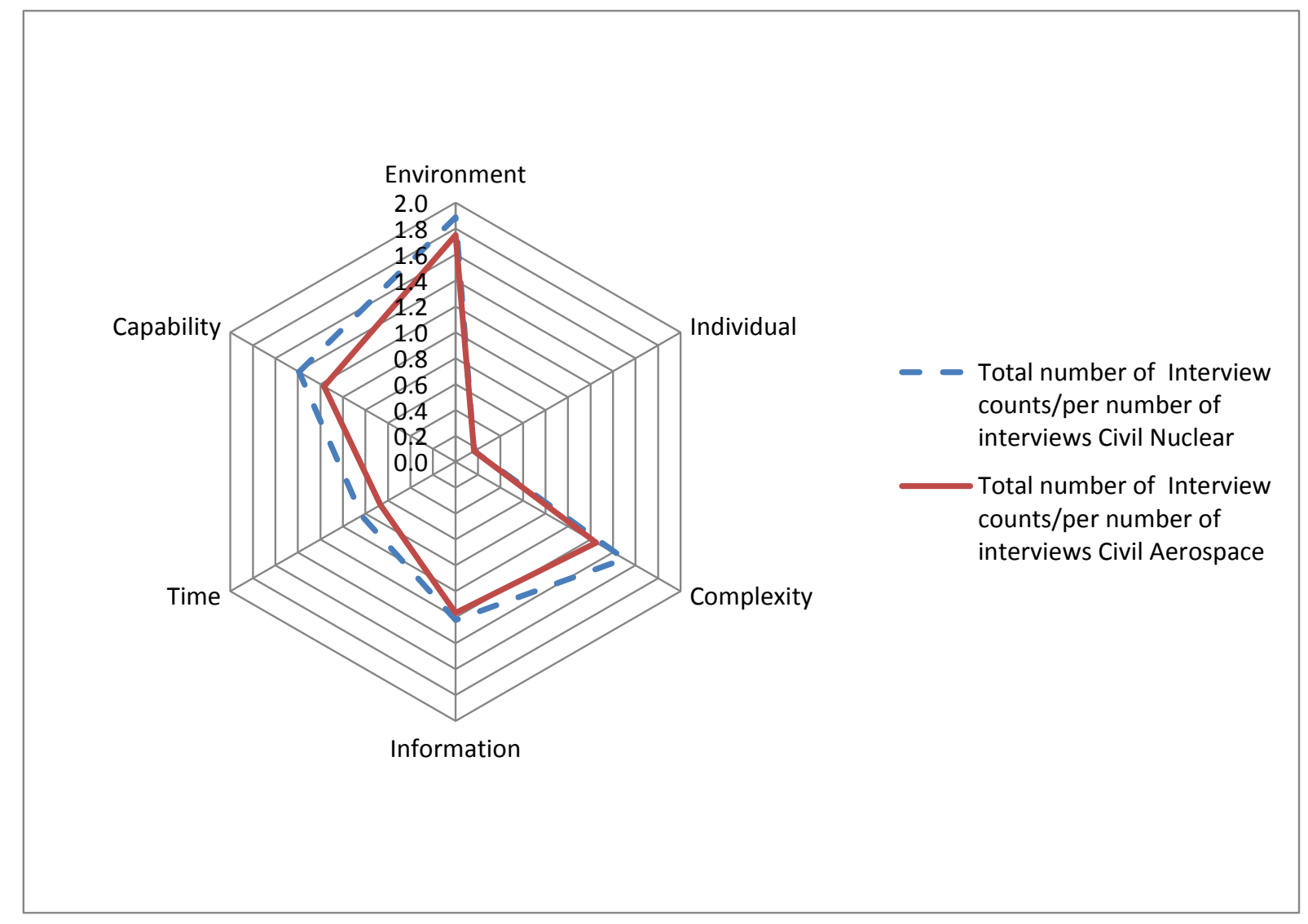

Figure 3: Number of counts per total number of interviews for each of six determinants of uncertainty 


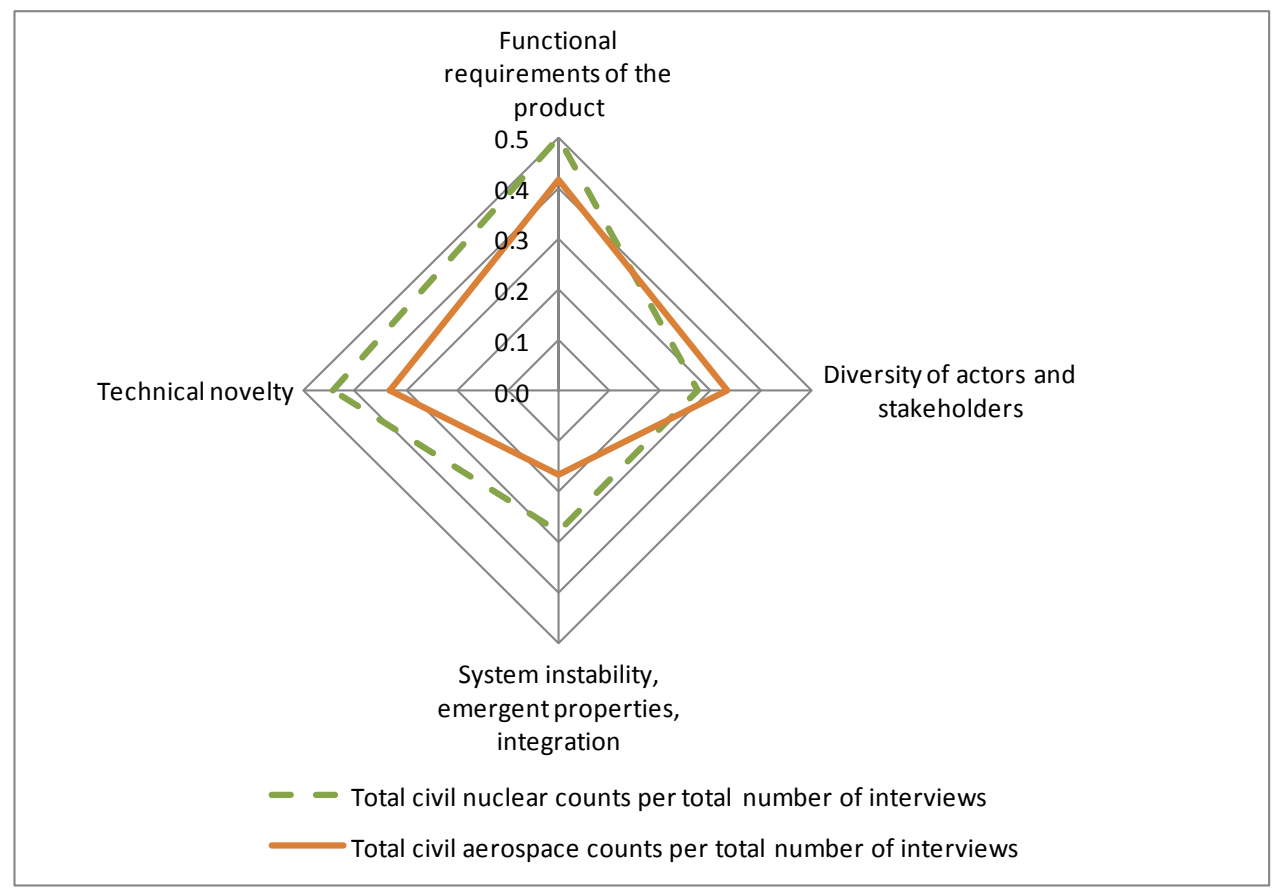

Figure 4: Components of Complexity as a determinant of project uncertainty: Total number of counts per total number of interviews in each sector. 


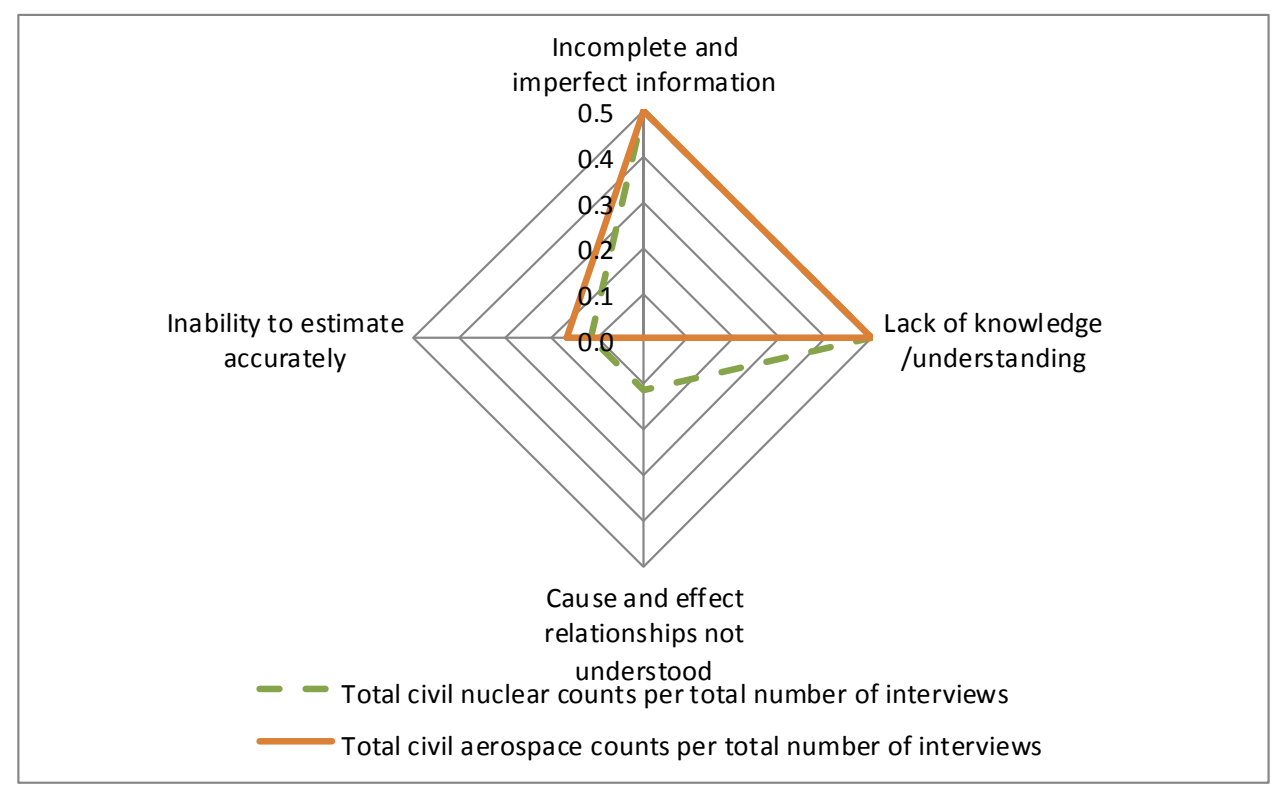

Figure 5: Components of Information as a determinant of project uncertainty: Total number of counts per total number of interviews in each sector. 


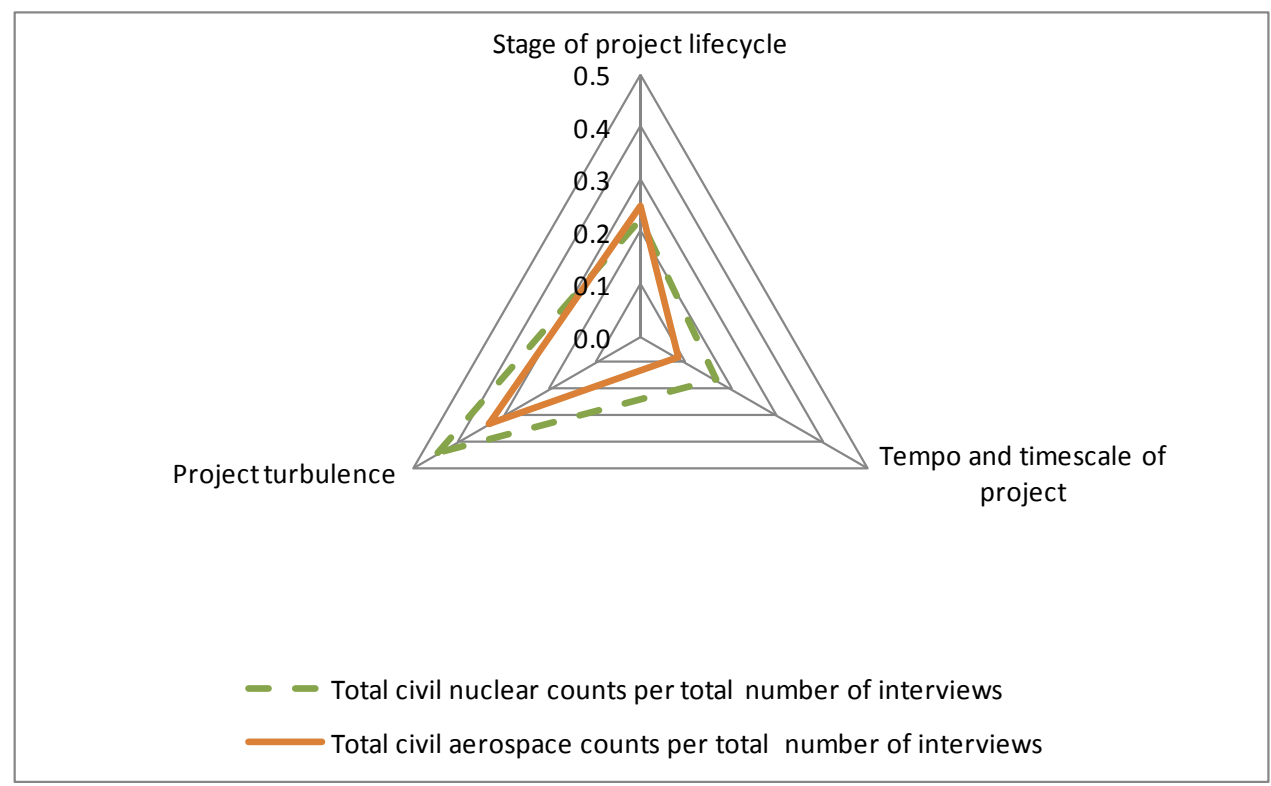

Figure 6: Components of Time as a determinant of project uncertainty: Total number of counts per total number of interviews in each sector. 


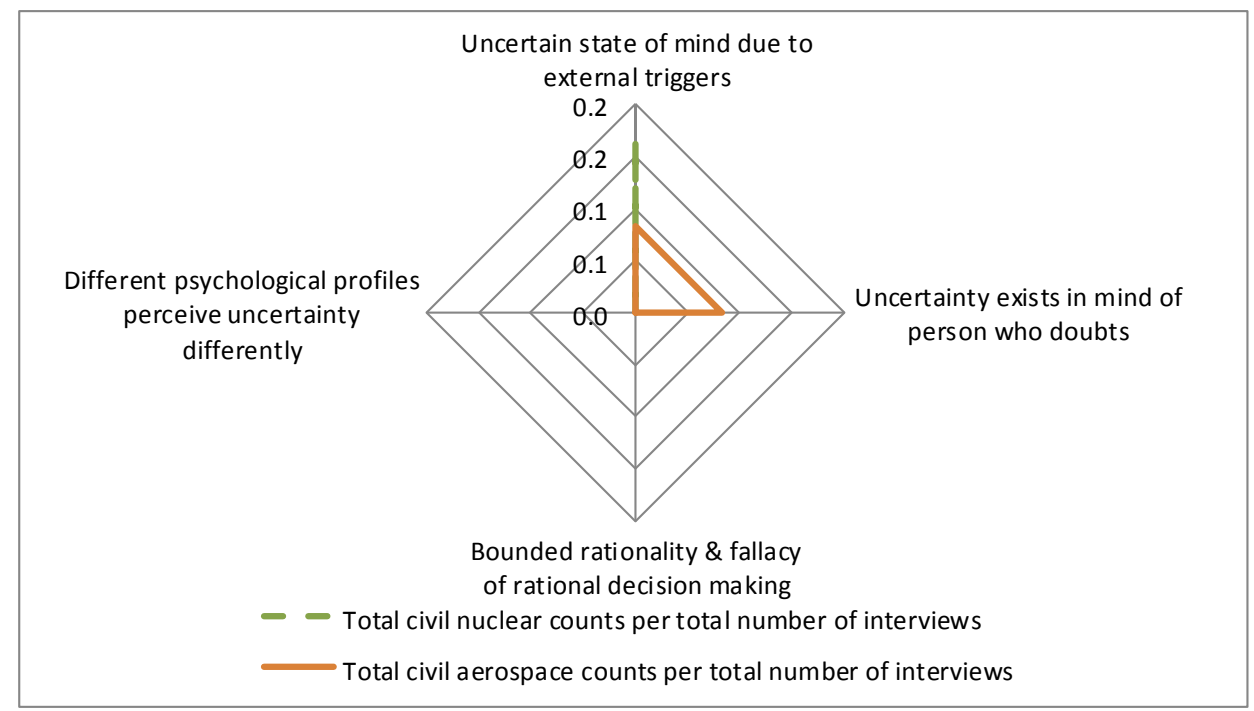

Figure 7: Components of Individual as a determinant of project uncertainty: Total number of counts per total number of interviews in each sector. 


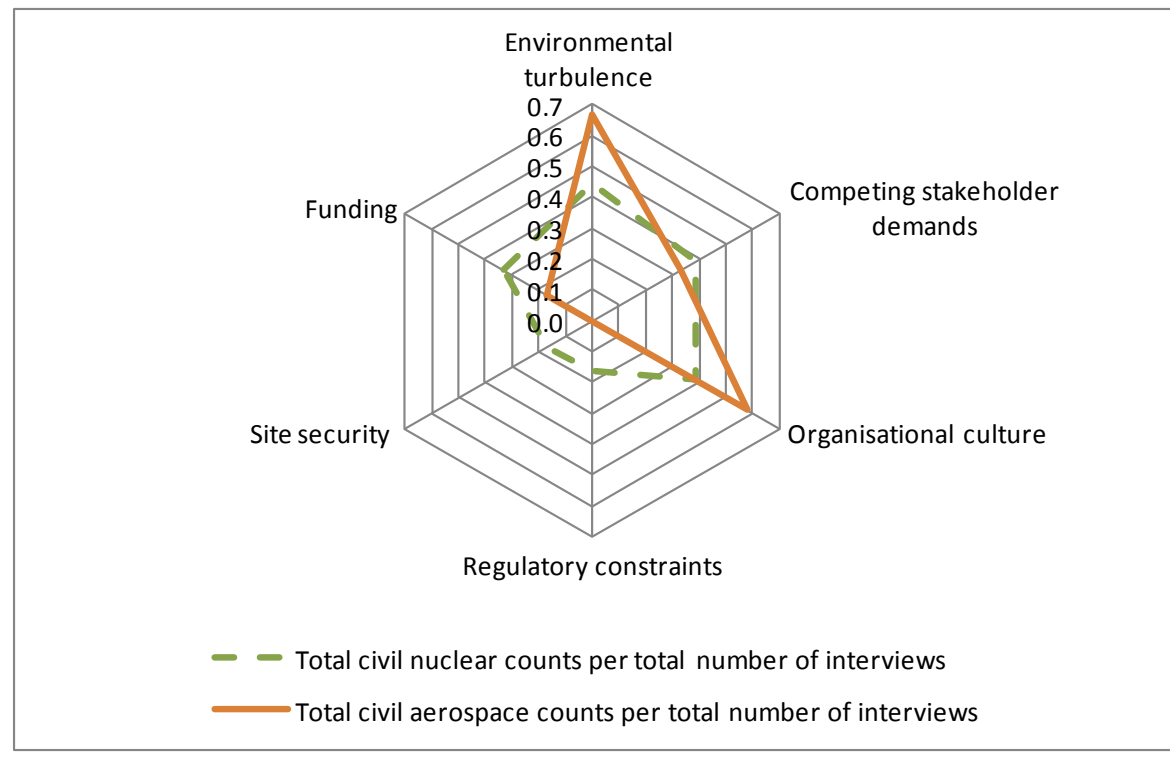

Figure 8: Components of Environment as a determinant of project uncertainty: Total number of counts per total number of interviews in each sector. 


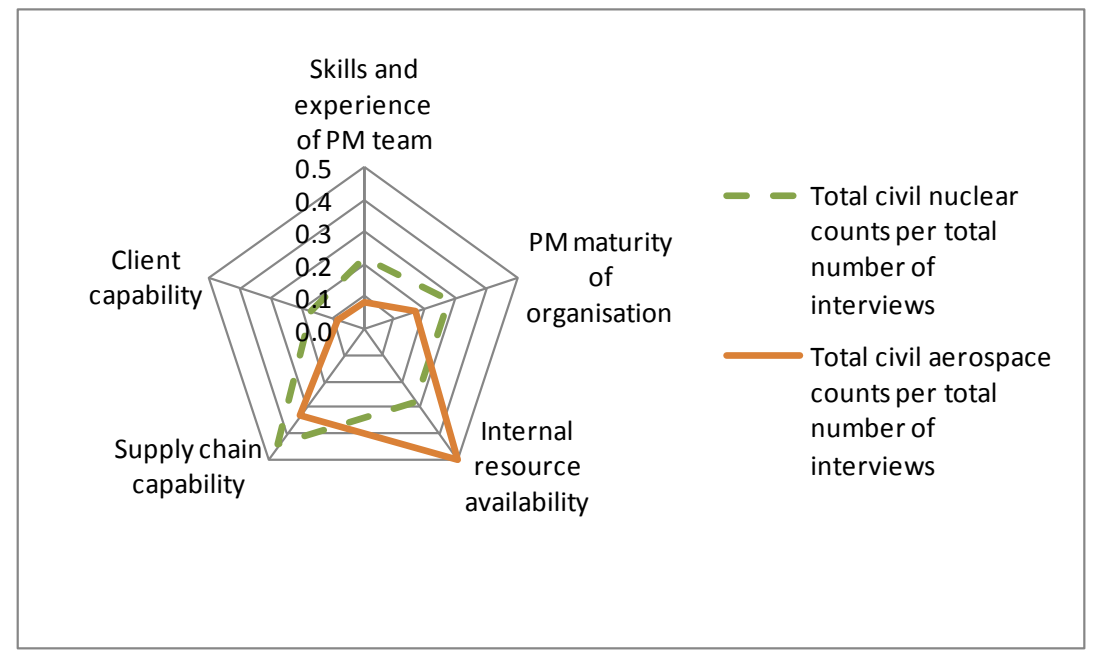

Figure 9: Components of Capability as a determinant of project uncertainty: Total number of counts per total number of interviews in each sector. 


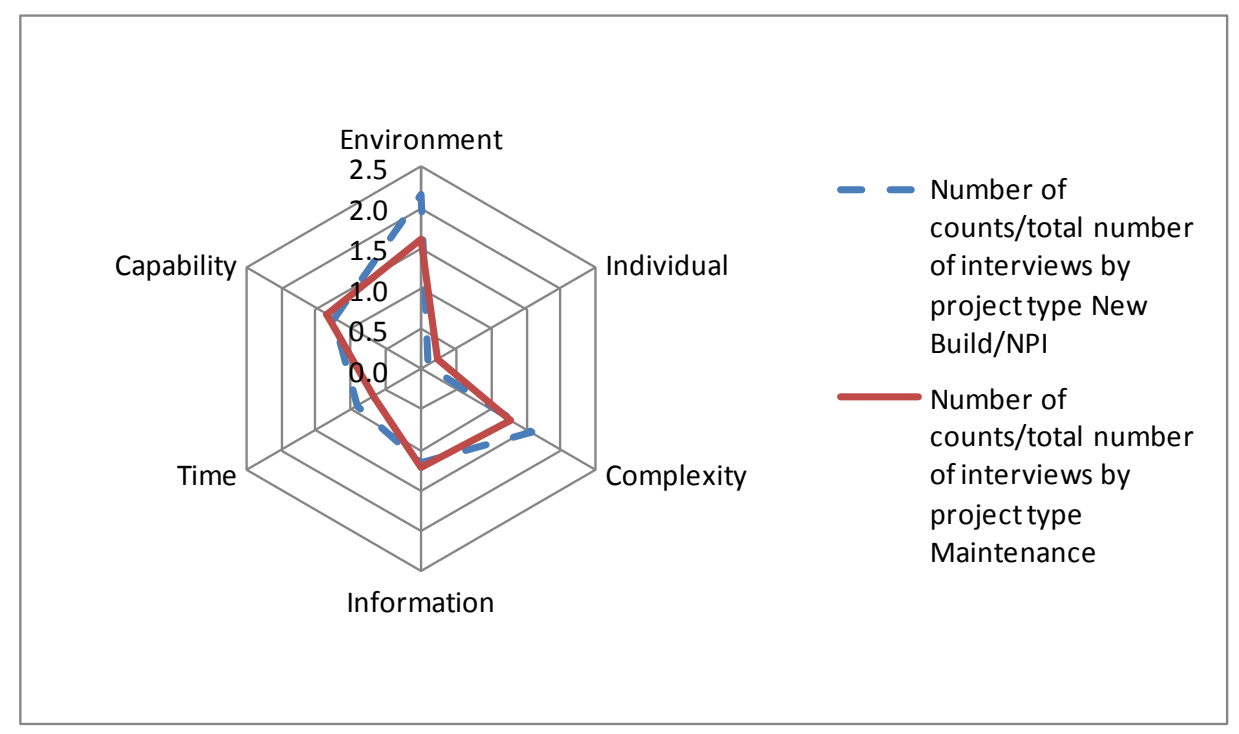

Figure 10: Number of counts per total number of interviews in new build/NPI projects and maintenance projects for each of the six determinants of uncertainty. 

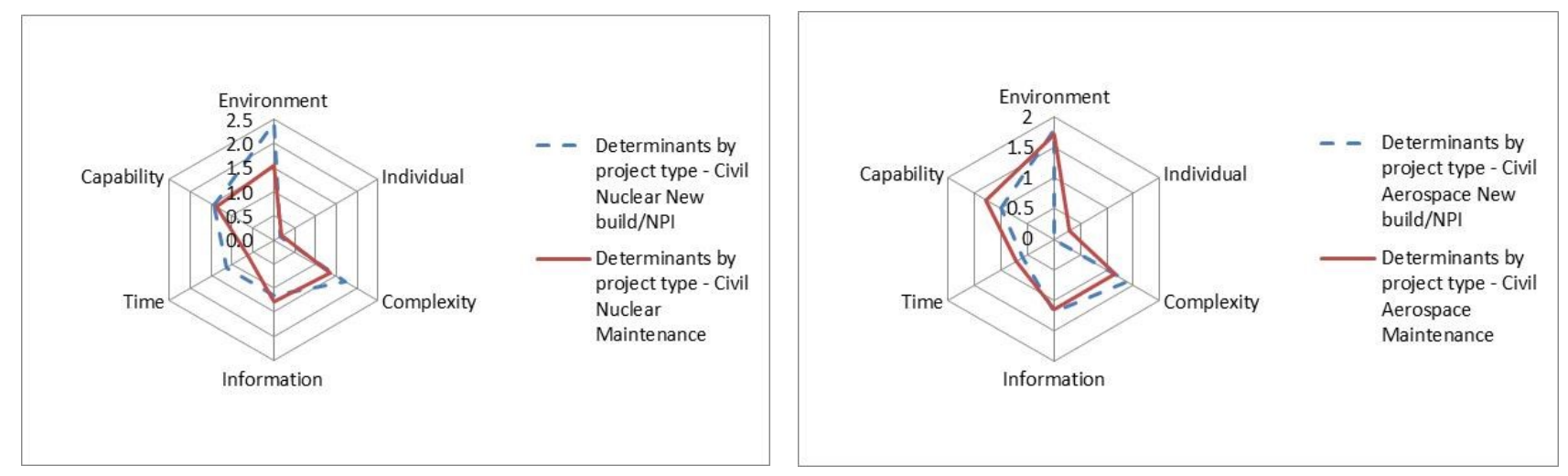

Figure 11: Number of counts per total number of interviews for each of the six determinants of uncertainty differentiated by both project type and industry sector 